\title{
RelaÇÕES SOCIAIS DE SEXO E DIVISÃO SEXUAL DO TRABALHO NOS CORREIOS: PARTICIPAÇÃO FEMININA, HIERARQUIA PROFISSIONAL E POLÍticas DE GESTÃO ${ }^{1}$
}

\author{
TADEu Gomes TeIXeIRA ${ }^{2}$
}

\begin{abstract}
Resumo
Analisa-se neste artigo como as relações sociais de sexo e as imagens de gênero têm influenciado a inserção e a participação de mulheres na área operacional da Empresa Brasileira de Correios e Telégrafos (ECT). Busca-se responder às seguintes questões: Como as relações sociais de sexo e as imagens de gênero influenciam a inserção e participação de mulheres na estatal? Qual a imagem do trabalho feminino na empresa e como isso interfere na ascensão profissional? Como as demandas sindicais e as políticas de gestão do trabalho se posicionam em relação às relações sociais de sexo? Verifica-se que a força de trabalho na ECT é majoritariamente masculina e as relações sociais de sexo apresentam uma imagem de gênero entre funcionários, gestores e sindicalistas que associam as atividades de trabalho da empresa aos homens, reiterando relações de sexo desiguais na estatal.
\end{abstract}

Palavras-chave: Correios. Relações sociais de sexo. Divisão sexual do trabalho. Gestão do trabalho.

Agradeço aos pareceristas pelas considerações e comentários que permitiram o aperfeiçoamento do artigo.

2 Professor-Adjunto de Ciências Sociais da Universidade Federal do Maranhão, Brasil. tagote@ gmail.com 


\title{
SOCIAL RELATIONS BASED ON SEX/GENDER AND SEXUAL DIVISION OF WORK IN THE BRAZILIAN POST OFFICE: FEMALE PARTICIPATION, PROFESSIONAL HIERARCHY AND MANAGEMENT POLICIES
}

\begin{abstract}
The focus of this article is to analyze how social relations based on sex/gender and gender images have influenced the inclusion and participation of women in the operational area of the Brazilian Post and Telegraph Company (ECT). We seek to answer the following questions: How do the social relations based on sex and gender images influence the inclusion and participation of women in the state company? What is the image of women's work in the company and how this image affects the career advancement? In what manner the union demands and the work management policies positions themselves in relation to gender issues? It is found that the workforce in ECT is mostly male and that the social relations based on sex presents a gender image among the employees, makers of labor management policies and trade unionists which associate the company work activities to men, reinforcing unequal sex/gender relations in this environment.
\end{abstract}

Keywords: Brazilian post office. Social relations based on sex/gender. Sexual division of work. Work management

\section{INTRODUÇÃo}

O incremento da participação feminina no mercado de trabalho brasileiro na segunda metade do século $X X$ ocorreu na esteira de movimentos políticos e sociais que questionaram as relações sociais de sexo dominantes. Nesse processo, as mudanças sociais e culturais foram importantes. As modificações nos perfis demográficos da população brasileira e nos valores sociais e culturais que proporcionaram às mulheres maior participação social - principalmente a partir das lutas dos movimentos feministas pela politização do cotidiano e da vida privada - criaram condições para a ampliação da participação feminina no mercado de trabalho brasileiro de forma majoritária a partir de 1980 (ARAÚJO, 2004; BRUSCHINI; LOMBARDI, 2007). 
Esse processo foi acompanhado pelo maior acesso das mulheres à escolaridade e às profissões técnicas, o que melhorou, qualitativamente, a participação feminina no mercado de trabalho. De acordo com Bruschini e Lombardi (2007), o aumento da escolaridade das mulheres permitiu que elas tivessem acesso a ocupações anteriormente vistas como masculinas, principalmente profissões de nível superior como arquitetura, engenharia, direito, medicina e outras ocupações de prestígio.

Apesar dos avanços da participação feminina no mercado de trabalho, as relações de sexo no âmbito das organizações ainda continuam a apresentar, predominantemente, condições que ensejam a manutenção do preconceito, das discriminações e dos menores salários recebidos pelas mulheres.

A compreensão dos mecanismos de reprodução das desigualdades entre homens e mulheres no interior das organizações requer o entendimento das relações sociais de sexo (HIRATA; KERGOAT, 2007; KERGOAT, 2009) que forjam as imagens de gênero (ABRAMO, 2007) e reverberam na divisão sexual do trabalho(HIRATA; KERGOAT, 2007; HIRATA, 2009).

Diante disso, discute-se neste artigo como as relações sociais de sexo e as imagens de gênero têm influenciado a inserção de mulheres na área operacional da Empresa Brasileira de Correios e Telégrafos (ECT).

A estatal é a empresa pública que detém o monopólio do setor postal brasileiro. Os Correios empregavam, diretamente, mais de 122 mil trabalhadores em 2013. A distribuição por área dos trabalhadores mostra que $85,96 \%$ dos funcionários estão na área operacional, sendo os $14,04 \%$ restantes da área administrativa.

A organização operacional da ECT para prestação de seus serviços inclui a rede de Agências para atendimentos aos clientes, onde são lotados os/as atendentes comerciais; os Centros de Tratamento de 
Cargas e Encomendas, onde os/as operadores de triagem e transbordo realizam a separação dos objetos postais de acordo com a área de destino e os Centros de Distribuição Domiciliária, onde trabalham os/ as carteiros/as responsáveis pela distribuição postal (TEIXEIRA, 2014).

Portanto, são três categorias profissionais na área operacional: atendentes comerciais, que representam $21,84 \%$ da força de trabalho; operadores/as de triagem e transbordo, que representam 12,23\%; e carteiros/as, que somam $50,47 \%$ da força de trabalho.

Os empregados da ECT são regidos pela Consolidação das Leis do Trabalho (CLT) e o ingresso na estatal ocorre mediante Seleção Externa, instrumento de contratação das empresas públicas.

Dos mais de 122 mil trabalhadores da ECT, somente cerca de $23 \%$ são mulheres, isto é, pouco mais de 28 mil trabalhadoras. Assim, apesar da crescente participação das mulheres no mercado de trabalho nas últimas décadas, verifica-se que a participação feminina na força de trabalho dos Correios é baixa.

Os dados ensejam os seguintes problemas de pesquisa: Como as relações sociais de sexo e as imagens de gênero influenciam a inserção e participação de mulheres na estatal? Qual a imagem do trabalho feminino na empresa e como isso interfere na ascensão profissional? Como as demandas sindicais e as políticas de gestão do trabalho se posicionam em relação às questões de gênero?

$\mathrm{O}$ artigo é parte de um projeto maior de compreensão das transformações recentes no sistema postal brasileiro e a pesquisa possui um recorte qualitativo e foi realizada entre 2008 e 2011. Os dados para a pesquisa foram obtidos a partir de pesquisa documental em relatórios de administração e dados internos da empresa relacionados à área de gestão do trabalho, entrevistas com trabalhadores e trabalhadoras, consulta a acervo de jornais comerciais, site e blog institucionais e observação da rotina de trabalho em Centros 
de Distribuição Domiciliária, unidades operacionais da empresa onde trabalham os carteiros e carteiras.

$\mathrm{Na}$ primeira parte do trabalho, discutem-se os aspectos conceituais acionados na análise dos dados, como as definições dos conceitos de relações sociais de sexo, imagens de gênero e divisão sexual do trabalho. Na segunda parte do artigo, apresenta-se a composição sexual dos trabalhadores da ECT da área operacional, enfatizando a atividade de carteiro/a.

Na sequência, analisa-se a distribuição dos cargos de chefia para homens e mulheres na empresa para discutir a influência das relações sociais de sexo na divisão sexual do trabalho na ECT e a adesão da empresa ao Programa Pró-Equidade de Gênero.

Por fim, analisam-se as políticas de gestão de pessoas a partir de um recorte de gênero, cotejando as reivindicações sindicais às garantias e conquistas das trabalhadoras informadas nos acordos coletivos de trabalho.

\section{RELAÇÕES SOCIAIS DE SEXo E IMAGENS DE GÊNERO: INSTRUMENTOS} ANALÍticos PARA A COMPREENSÃO DO TRABALHO FEMININO

O conceito de relações sociais de sexo refere-se à tensão e antagonismo existentes nas relações sociais estabelecidas entre os distintos grupos sociais constituídos por homens e por mulheres, de acordo com Kergoat (2009) e Hirata e Kergoat (2007).

As relações sociais de sexo devem ser entendidas como constructos sociais e não devem ser confundidas com categorizações vinculadas às supostas essencialidades biológicas. São relações institucionalizadas nas dinâmicas pessoais e nas condutas acionadas na ação social em sintonia com os processos históricos (DEVREUX, 2005). 
As relações sociais de sexo são institucionalizadas nas dinâmicas pessoais e nas condutas acionadas na ação social, como argumenta Kergoat (2009), e derivam de construções sociais e não de supostas essencialidades biológicas. Isso implica, portanto, a necessidade de considerar a tensão e o antagonismo existente entre os grupos sociais formados por homens e mulheres.

De acordo com Kergoat (2009) e Devreux (2005), as relações sociais de sexo são atravessadas por uma hierarquização entre os sexos, caracterizando uma relação de dominação e de poder e perpassam todas as relações sociais, isto é, há uma consubstancialidade, como afirma Kergoat (2010), entre as relações de sexo, classe e raça.

As relações sociais de sexo, assim, possuem quatro características fundamentais, como destaca Michelè Ferrand: 1) são antagônicas, isto é, opõem os grupos de homens e mulheres; 2) são transversais, abarcando distintas esferas sociais; 3) são dinâmicas e construídas no processo socio-histórico; 4) são bicategorizadas, ou seja, atribuem posições hierárquicas diferenciadas na sociedade para homens e mulheres (RIAL; LAGO, GROSSI, 2005).

Além disso, as relações sociais de sexo possuem uma base material, fundada na divisão sexual do trabalho. De acordo com Hirata e Kergoat (2007), o conceito de divisão sexual do trabalho refere-se à distribuição de homens e mulheres no mercado de trabalho e entre categorias profissionais e suas variações no tempo e no espaço, vinculando-se também à distribuição do trabalho doméstico. Além disso, o conceito permite compreender como a distribuição de homens e mulheres no mercado de trabalho ocorre de forma hierarquizada nas atividades profissionais, vinculando-se, assim, aos sistemas de hierarquização das relações sociais. Como afirmam as autoras, "[...] a divisão sexual do trabalho é a forma de divisão do trabalho social decorrente das relações sociais entre os sexos [...]." (HIRATA; KERGOAT, 2007, p. 599). 
Assim, a divisão sexual do trabalho vincula-se aos processos sócio-históricos que atribuem aos homens o espaço público e produtivo e às mulheres resta o âmbito privado, da reprodução, com a consequente apropriação pelos homens de atividades sociais e profissionais de maior prestígio. A divisão sexual do trabalho, assim, comporta dois princípios analíticos: um de separação, que remete a trabalhos de homens e mulheres e outro de hierarquização, com o trabalho masculino sendo mais valorizado que o feminino.

As relações sociais de sexo e a divisão sexual do trabalho, segundo Hirata (2009) e Hirata e Kergoat (2007), são indissociáveis porque formam um sistema que permite compreender as relações sociais assimétricas, desiguais e hierarquizadas entre homens e mulheres.

Importante aspecto a destacar nas relações sociais de sexo e que possui implicações para a divisão sexual do trabalho são as imagens de gênero compartilhadas pelo imaginário social e que se desdobram, por conseguinte, na constituição do imaginário empresarial sobre as relações sociais, como nos mostra Abramo (2007), o que influencia, decisivamente, no lugar atribuído à mulher na divisão sexual do trabalho.

Abramo (2007) argumenta que há no imaginário social uma representação da mulher como sendo destinada à função de cuidar do universo doméstico e privado, espaço que socialmente é invisível, considerado inferior e onde não se reconhece o valor das atividades realizadas, o que restringe o tempo e os recursos das mulheres para investir na própria capacitação e em trabalhos remunerados. Em consequência disso, o trabalho da mulher na sociedade seria pouco valorizado, tanto economicamente quanto socialmente.

Dessa maneira, as imagens de gênero compartilhadas na sociedade, conforme analisa Abramo (2007), são responsáveis pela orientação de ações dicotomizadas e hierarquizantes das relações 
entre homens e mulheres que reforçam a manutenção e reprodução das desigualdades entre os sexos, abarcando também o mundo do trabalho e o universo empresarial ${ }^{3}$.

Na mesma direção, Araújo (2004, p. 9) argumenta que:

[...] a segmentação das ocupações por sexo é [...] recriada ao longo do processo de reestruturação produtiva [...] e as mudanças no sistema de produção têm requerido das mulheres uma série de habilidades que, adquiridas através do seu processo de socialização no espaço privado, apelam para um reforço de comportamentos culturalmente definidos como femininos (grifo do autor).

Esses aspectos são retomados na análise de Abramo (2007) sobre a inserção da força de trabalho das mulheres no mercado de trabalho: esta seria uma força de trabalho secundária, não considerada como a principal renda da família, já que as relações sociais de sexo atribuem o papel de provedor ao homem, que teria a responsabilidade de possuir a maior renda - ou única - da unidade familiar, enquanto à mulher caberia o papel de cuidar das atividades domésticas e de reprodução, participando das atividades produtivas apenas de forma complementar à renda principal da família.

As relações sociais de sexo, portanto, influenciam também as relações de trabalho entre os sexos e as condições de inserção das mulheres nas atividades laborais tanto quanto as relações de classe. Além disso, ao mesmo tempo em que estruturam as relações sociais, as relações sociais se sexo condicionam as imagens de gênero presentes

Após intensa luta dos movimentos feministas a partir da década de 1960, observou-se crescente inserção das mulheres no mercado de trabalho que precisa ser compreendido também, como nos mostra Araújo (2004, p.4), a partir de processos como “as mudanças econômicas e demográficas, a intensificação dos intercâmbios internacionais bem como das mudanças culturais e nos valores relativos ao papel da mulher na sociedade, impulsionadas pelas lutas feministas desde os anos 1970 [...]". Ainda de acordo com essa autora, desde o início da década de 1980 a inserção feminina no mercado de trabalho remunerado tem passado por mudanças significativas, período em que se começou a falar de feminização do mercado de trabalho. 
na sociedade, responsáveis pela atualização das desigualdades entre homens e mulheres.

A partir desses traços constitutivos das relações sociais de sexo e das imagens de gênero, cabe observar a influência que continuam exercer na formação do imaginário social e empresarial e, consequentemente, nas relações sociais estabelecidas no universo das organizações empresariais, mesmo quando o Estado é o agente econômico e pioneiro na aplicação de políticas pró-equidade de gênero.

\section{Relações sociais de Sexo e imagens de gênero nos Correios}

A composição da força de trabalho nos Correios permite apreender a divisão sexual do trabalho e os cargos e funções que homens e mulheres ocupam na estrutura da empresa. A diferenciação é importante devido à natureza distinta das atividades desempenhadas em cada posto de trabalho, o que pode impactar de maneira distinta as imagens e representações sobre o trabalho masculino e feminino.

Os empregados da ECT em junho de 2013 totalizavam 122.038 funcionários, dos quais 23,21\% eram mulheres, isto é, 28.325 trabalhadoras. Isso mostra que a distribuição por sexo da força de trabalho dos Correios se mantém estabilizada desde 2002, quando a taxa era de quase $23 \%{ }^{4}$.

Na Europa, a participação feminina no setor postal e de telecomunicações é de cerca de $30 \%$, o que mostra a baixa participação das mulheres no setor também no contexto internacional.

$\mathrm{O}$ baixo índice de participação das mulheres na força de trabalho dos Correios pode ser mais bem apreendido ao se observar a distribuição por sexo dos/as trabalhadores/as que exercem atividades

Em 2003 as mulheres representavam quase $22 \%$ da força de trabalho, atingindo $22,5 \%$ no ano seguinte. 
operacionais diretamente relacionadas às atividades finais da empresa, isto é, os cargos de atendente comercial, operador/a de triagem e transbordo e carteiro/a:

Tabela 1 - Sexo dos ocupantes do cargo de Agente de Correios por Atividade (Maio 2010) ${ }^{5}$

\begin{tabular}{|l|l|l|l|l|l|l|}
\hline \multicolumn{1}{|c|}{$\begin{array}{c}\text { Agente de } \\
\text { Correios }\end{array}$} & \multicolumn{2}{|c|}{ Homens } & \multicolumn{2}{c|}{ Mulheres } & \multicolumn{2}{c|}{ Total } \\
\hline Carteiro/a & 50.396 & $89,93 \%$ & 5.642 & $10,07 \%$ & 56.038 & $100 \%$ \\
\hline Atendente & 12.246 & $54,05 \%$ & 10.410 & $45,95 \%$ & 22.656 & $100 \%$ \\
\hline $\begin{array}{l}\text { Operador } \\
\text { de triagem e } \\
\text { transbordo }\end{array}$ & 10.004 & $77,43 \%$ & 2.916 & $22,57 \%$ & 12.920 & $100 \%$ \\
\hline $\begin{array}{l}\text { Total do } \\
\text { efetivo }\end{array}$ & 72.646 & $66,94 \%$ & 18.968 & $17,48 \%$ & 108.516 & $100 \%$ \\
\hline
\end{tabular}

Fonte: Elaboração própria.

Verifica-se pelos números apresentados na Tabela 1 uma distribuição desigual da participação de homens e mulheres nas atividades da área operacional. Em números absolutos, os homens compõem quase $67 \%$ do efetivo operacional, enquanto as mulheres somam pouco mais de $17 \%$ (o restante dos trabalhadores etrabalhadoras ocupavam cargos administrativos).

Ao se analisar por atividade a distribuição de trabalhadores e trabalhadoras, constata-se a concentração de homens nos cargos de carteiro/a e operador/a de triagem e transbordo, ou seja, a presença de $89 \%$ e $77 \%$, respectivamente, de homens nesses cargos. Somente a atividade de atendente comercial possui uma participação maior de mulheres, correspondendo a quase $46 \%$ do total.

Como compreender esses números tão discrepantes de homens e mulheres nas atividades operacionais da ECT? Os dados

\footnotetext{
$5 \quad$ O acesso aos dados necessários à elaboração da tabela só foram obtidos até maio de 2010. A proporcionalidade, contudo, foi mantida apesar do aumento do número de trabalhadores e trabalhadoras.
} 
apresentados na tabela 1 precisam ser compreendidos a partir das relações sociais de sexo e das imagens de gênero vinculadas às atividades de trabalho.

Nessa direção, a ECT nos informa que a atividade de carteiro/a foi considerada até recentemente uma "atividade masculina". A presença de mulheres no cargo remonta ao ano de 1992, quando a proibição às mulheres em participar da seleção externa para carteiro/a foi questionada e superada. Na ocasião, apenas dezessete mulheres ingressaram na empresa como carteiras.

Em 2004, as mulheres já somavam dez por cento do total de carteiros/as, oquerepresentava 4.700trabalhadoras(IMPORTÂNCIA..., 2004). O percentual continua o mesmo, portanto, desde 2004, com pequena variação nos números absolutos (evolução de 4.700 para 5.642 trabalhadoras em maio de 2010).

A atividade de carteiro/a esteve associada a uma imagem masculina por estar vinculada a atributos supostamente inerentes aos homens, como a força física necessária ao desempenho das atividades do cargo (permanecer em pé em longas jornadas de trabalho, percorrer longas distâncias, realizar esforços físicos ao carregar a bolsa com objetos postais, etc.). De forma semelhante, a atividade de operador/a de triagem e transbordo é considerada a priori uma atividade masculina por estar associada, principalmente, ao transporte de caixas com correspondências, carregamento e descarregamento de caminhões, etc.

Em 1992, quando pela primeira vez as mulheres participaram da seleção externa para o cargo de carteiro, a Folha de São Paulo acompanhou a trajetória da primeira mulher da região do $A B C D$ paulista a participar do concurso:

Carla Allan, 24, causou espanto na última quinta-feira, quando resolveu enfrentar uma longa fila e fazer inscrição para o concurso de carteiro. Os motivos que levaram a 
estudante a optar pela profissão são claros para ela: receber um salário razoável que lhe permita continuar os estudos. [...] Caso passe no concurso, [...] Carla será a primeira 'carteira' do ABCD. "E possivelmente até do Brasil porque um funcionário de São Paulo me disse que os Correios já fizeram uma experiência com mulheres que não deu certo", disse. Uma vez aprovada, Carla enfrentará uma jornada de seis horas carregando uma mala de cartas de até 25 quilos. "Já trabalhei com vendas de imóveis de casa em casa, as duas coisas são parecidas", afirmou. Para ela, o peso não é empecilho. "Faço musculação e ginástica há nove anos, estou preparada fisicamente". Problema mesmo, segundo ela, será trabalhar a pé, sujeita às mudanças do tempo. Para evitar outros problemas, antes de fazer a inscrição, Carla ligou para a regional dos Correios em São Paulo para perguntar se aceitavam mulheres e teve resposta positiva. Em Santo André, onde se inscreveu, a coisa não foi bem clara. A princípio, segundo Carla, os funcionários não sabiam o que fazer, mas acabaram aceitando a inscrição. Entre o desconhecimento dos funcionários e a ironia dos concorrentes, Carla saiu vitoriosa, com a inscrição na mão. A estudante se considera capacitada para o exame. [...]. Além disso, ela afirma que está determinada a iniciar a carreira. "Não sei bem o que é, mas tem algo além do dinheiro, é uma profissão interessante", disse. A família de Carla, que mora em Ribeirão Pires, segundo ela, não se assustou com a idéia. A irmã mais nova só não se inscreveu porque não tinha como conciliar os horários da escola e de cuidar da filha. Os amigos também não estranharam a decisão de Carla. "Acho que não haverá discriminação. No início, todo mundo acha meio esquisito, mas depois vê que não tem nada de errado", afirmou. O importante agora, segundo ela, é se preparar para o exame e passar. "Não tenho nem namorado para atrapalhar que eu faça minha vida agora", disse (SALÁRIO..., 1992, grifo nosso).

No dia 15 de julho de 1992, a Folha de São Paulo publicou novamente uma nota sobre Carla,

A primeira carteira do $\mathrm{ABCD}$ [...], a única mulher a executar esse trabalho [...]. O fato de a profissão de carteiro ser desempenhada apenas por homens não impediu que 
Allan se inscrevesse para o concurso da ECT. "Quando fui fazer a inscrição, o funcionário recebeu a minha ficha e ficou espantado", disse. [...] O Administrador-postal da ECT [...] que coordena o Centro de Distribuição Domiciliar [...] afirmou que a carteira tem realizado um bom trabalho. “Os moradores estão gostando. Eles dizem que a mulher é mais cuidadosa" (CARTEIRA..., 1992, grifo nosso).

As duas matérias são ricas na apresentação das relações sociais de sexo e na descrição das imagens de gênero atribuídas às mulheres e sua influência na divisão sexual do trabalho, especialmente no caso da primeira mulher da região do ABCD paulista a se tornar carteira. Nesse sentido, o pioneirismo de Carla como a primeira carteira da região foi suficiente para que tivesse seus primeiros dias de trabalho nos Correios acompanhado por um dos maiores jornais do país.

As atitudes e comportamentos relatados mostram como as relações sociais de sexo que reiteram a hierarquia entre os sexos nas atividades profissionais exerceram enorme pressão sobre a candidata. Ela rompeu com as expectativas sociais e se aventurou em uma atividade profissional masculinizada. Pela ousadia em tentar se inscrever no concurso, "causou espanto". Foi enorme o "espanto" ao ponto de os funcionários ficarem "sem saber o que fazer" e a situação provocar a "ironia dos concorrentes" por meio de piadas e "brincadeiras" discriminatórias.

Dessa maneira, a divisão sexual do trabalho associada às imagens de gênero hegemônicas agiam tão fortemente no caso que o simples fato de a candidata se inscrever no concurso é noticiado pelo jornal como uma conquista, tornando a candidata "vitoriosa". Uma vitória, de fato, já que na ocasião houve a tentativa de dissuasão de Carla por um funcionário da empresa, que a informou de "uma experiência com mulheres que não deu certo". Quando a trabalhadora já estava em exercício como carteira, a reportagem volta ao local de trabalho para saber da adaptação da trabalhadora às atividades e 
descobre que "os moradores estão gostando. Eles dizem que a mulher é mais cuidadosa"! Os estereótipos de gênero atuaram para dificultar a inscrição da jovem trabalhadora e continuaram a pressionar por um modelo de relações sociais de sexo através do reforço, como analisa Araújo (2004), de comportamentos definidos culturalmente como femininos, exemplificados no caso pela carteira ser "cuidadosa".

Um dos principais argumentos para associar a atividade de carteiro ao universo masculino é a suposta necessidade de um adequado condicionamento físico. $\mathrm{Na}$ reportagem, a candidata informa que é praticante de atividades físicas há nove anos, o que a ajudaria a "enfrentar uma jornada de seis horas carregando uma mala de cartas de até 25 quilos", "ficar em pé" durante a jornada de trabalho, embora o seu medo estivesse centrado nas "condições climáticas adversas". Interessante destacar que foi só na segunda metade da década de 2000 que testes físicos passaram a ser parte do processo seletivo de carteiros/as, mas foi o aspecto que Carla precisou destacar para garantir a legitimidade de sua atuação como carteira.

Nas últimas seleções para o cargo de Agente de Correios nas atividades de carteiro/a e operador/a de triagem, a avaliação do preparo físico dos candidatos e candidatas têm sido uma das etapas eliminatórios da seleção. Na seleção externa ocorrida em 2011, a Avaliação da Capacidade Física e Laboral dos candidatos foi realizada em parceria com o Exército em todos os estados da federação. A associação entre as duas instituições, além dos aspectos logísticos, também comporta aspectos simbólicos associados à força e autoridade. Os testes físicos exigidos para homens e mulheres incluíam corrida, barra fixa e dinamômetro (aparelho que mede a força muscular dos candidatos nos ombros e costas). As exigências para cada sexo são ligeiramente distintas, o que não elimina o fator psicossocial associado à força e resistência física - características supostamente masculinas dos testes. 
No blog institucional dos Correios, candidatos e candidatas questionaram e discutiram as exigências da avaliação física:

Ficou nítido que o público feminino não é bem-vindo nos Correiosna função de carteiro, haja vista estabelecerem uma diferença insignificante entre homem e mulher no teste de Dinamômetro escapular (30kgf e $25 \mathrm{kgf}$, respectivamente, ou seja, apenas $5 \mathrm{kgf})$. Será que a diferença de força muscular nesse caso é tão pequena? Em Santa Maria-RS, de cerca de 50 mulheres apenas 5 conseguiram atingir a marca (nem um $1 \mathrm{kgf}$ a mais), a maioria dos homens foi aprovada no Escapular. E com louvor, embora tivessem que atingir a marca de 30kgf. A imensa maioria fez de 35 a $45 \mathrm{kgf}$. Talvez esteja equivocada, mas está muito descarado (os números falam por si só). P.S. Obrigado por abrir esse espaço para comentário, sei que não vão publicá-lo. Todavia estejam certos que tentarei expor minha opinião na maioria das redes de comunicação; em última instância, até a greve de fome recorrerei por essa tamanha falta de respeito com a MULHER. Estou chegando à conclusão que cometi um erro: SERÁ QUE COMETI O ERRO DE TER NASCIDO MULHER? (Candidata Eliana) (CORREIOS, 2011, grifo do autor).

As intervenções prosseguiram e houve uma candidata favorável aos procedimentos adotados pela empresa, enquanto outras foram mais críticas:

Eliana, concordo com os testes físicos para o cargo de carteiro, e acho que realmente não pode haver muita diferença nos padrões de aferição entre homens e mulheres nesses testes, pois no serviço também não há. Existe apenas uma diferença de dois quilos a menos no limite de peso para a mulher carregar na bolsa que é diferente do homem, mas o serviço é a mesma coisa e o tempo de execução o mesmo. A empresa não está discriminando as mulheres com os testes, mas selecionando os candidatos de acordo com a realidade do serviço, que não é mais brando para a mulher. Existem excelentes carteiras nos correios, verdadeiras guerreiras (Candidata Rosa). 
Diante da discussão, a resposta da empresa aos candidatos e candidatas foi expressa de maneira padronizada nos seguintes termos:

As atividades rotineiras dos cargos de carteiro e operador de triagem e transbordo exigem que o profissional tenha condições físicas para desempenhar as tarefas do dia-adia.

Os parâmetros da Avaliação da Capacidade Física e Laboral (ACFL) foram definidos após estudo médico. Os testes verificam o condicionamento aeróbico, a força, a flexibilidade, a potência muscular e a velocidade, que é o mínimo necessário para execução de tarefas funcionais e laborais destas atividades. O candidato com desempenho insatisfatório apresenta pré-disposição para fadiga física e agravo de natureza osteomusculoligamentar. Tal avaliação é necessária em razão de que as atividades exigem força muscular (CORREIOS, 2011).

A polêmica envolvendo os testes físicos para a seleção das candidatas aos cargos operacionais atualizam as imagens de gênero presentes desde 1992 e que são centrais para compreender a reduzida presença de mulheres na empresa: a suposta necessidade de um condicionamento físico "masculinizado".

No entanto, o peso da carga de trabalho manejada não afeta somente as mulheres, evidentemente, mas ambos os sexos. Em razão disso, desde a década de 1990 os sindicatos dos trabalhadores dos Correios têm pleiteado e conseguido diminuir a carga transportada manualmente pelos trabalhadores e trabalhadoras. Nesse sentido, por exemplo, em 1992 - quando as mulheres ingressaram na atividade de carteiro - o peso da bolsa desses trabalhadores era de vinte e cinco quilogramas. Depois de sucessivas negociações e acordos, o acordo coletivo de 2009-2011 previa dez quilos para homens e oito para mulheres, o que evidencia uma constante luta dos trabalhadores e trabalhadoras para um melhor redimensionamento da carga 
transportada como forma de preservar as condições de saúde de homens e mulheres.

Ao acompanhar as rotinas de trabalho de carteiros e carteiras em Centros de Distribuição Domiciliar em São Paulo, Rio de Janeiro e Espírito Santo, foi possível constatar a representação das imagens de gênero que associam a atividade de carteiro/a a uma imagem masculinizada e à força, processo que reforça a divisão sexual do trabalho na empresa. As brincadeiras entre carteiros/as sobre os distritos - uns mais "pesados" que outros - suscita comentários acerca dos "distritos de mulher", isto é, aos distritos que seriam menos pesados para atender às supostas fragilidades das trabalhadoras. São referências feitas - quase sempre por meio de brincadeiras - aos supostos benefícios que as mulheres teriam ao trabalhar em distritos mais fáceis, com terrenos planos e com menos peso nas bolsas, o que alguns trabalhadores em tom jocoso chamam de "distritos de mulherzinha" ou "distritos de moça", menosprezando a atuação feminina na empresa e inferiorizando a atuação das trabalhadoras.

Tais imagens de gênero não condizem com os depoimentos das carteiras sobre suas rotinas:

[...] eu zero distrito que homem passou e não zerou. (Marta, novembro 2011).

Bom, no meu caso não tem diferença. Já fui motorizada e trabalhava de igual para igual ou até mais, carregando muito peso. Confesso, porém, quejá ouvi muitas piadinhas, mas nunca dei ouvido. Concordo que a ECT precisa realmente dar uma atenção maior para nós mulheres, pois quando fiz o concurso parecia uma coisa, mas a realidade é outra. Não existe nenhum acompanhamento, para saber se nós estamos de fato sendo respeitadas (peso, distrito e etc.).

(Lilia, novembro 2011).

O meu setor (distrito) é bem pesado e tem um (carteiro) morcegando em um setor bem mais leve. Enquanto eu me 
mato de trabalhar ele fica no bem bom. Acho que deveria haver redistritamento mais frequente para evitar essas injustiças.

(Camila, novembro 2011).

As experiências das trabalhadoras, apresentadas nos depoimentos, apontam para uma percepção das atividades de trabalho em suas rotinas como iguais ou até mais pesadas, o que contrasta com as imagens de gênero de trabalhadoras "frágeis", que ainda repercutem no cotidiano da área operacional dos Correios.

Trata-se da mesma imagem de gênero apresentada anteriormente pelo gestor do Centro de Distribuição Domiciliária onde a primeira carteira da região do $\mathrm{ABCD}$ foi lotada: para ele, os moradores aprovavam o trabalho dela por ser "mais cuidadosa" com as cartas. Evidentemente, tais imagens não são forjadas no espaço de trabalho da ECT, mas encontra condições para sua reprodução nas relações sociais de sexo vivenciadas no espaço de trabalho da estatal.

\section{Divisão Sexual do Trabalho e Hierarquia Profissional}

Uma das consequências das imagens de gênero e das relações sociais de sexo que atribuem às mulheres uma inserção secundária no mercado de trabalho é a assimetria na divisão sexual do trabalho e, por conseguinte, na hierarquia profissional. Por ser tratar de uma empresa pública, a política salarial é estabelecida para carreiras de forma a não contemplar parâmetros discricionários dos gestores e aspectos subjetivos, o que impede uma remuneração diferenciada para homens e mulheres que ocupam o mesmo cargo e estão no mesmo nível na carreira.

No entanto, a ascensão e ocupação de cargos de livre nomeação estão passíveis de influência das representações que perpetuam a ordem desigual de gênero. Assim, a política salarial pode revelar muito pouco sobre as relações de gênero na ECT, enquanto a divisão 
sexual dos funcionários por cargos de chefia ou em funções específicas pode evidenciar os mecanismos de reprodução das desigualdades entre os sexos.

Para entender a natureza das funções na estrutura profissional da empresa é preciso considerar que há duas categorias de gratificações: as que consistem em ascensão profissional e as exercidas pelos trabalhadores sem caráter de ascensão.

No primeiro grupo, encontram-se as funções técnicas e gerenciais. São funções exercidas, por exemplo, por diretores regionais, coordenadores de área, gerentes corporativos e regionais, gerentes de unidades operacionais, supervisores operacionais, instrutores, etc. São funções que se destacam pela presença de subordinados.

O segundo grupo de funções, no entanto, apesar de gratificadas, não implicam exercício de chefia. São as atividades especiais, atribuídas aos empregados em razão da utilização de equipamentos específicos ou condições de trabalho especiais, vinculadas às tarefas dos cargos. Os/as trabalhadores/as que executam atividades especiais recebem apenas um valor convencional de gratificação estipulado nas negociações coletivas. As ditas atividades especiais são exercidas por funcionários/as motorizados/as (veículos ou motos), operadores/as de empilhadeira, operadores/as de equipamentos de segurança postal, operadores/as de teleatendimento, quebra de caixa em agências etc.

A tabela 2 mostra a distribuição de homens e mulheres nas funções e atividades gratificadas na ECT:

Tabela 2 - Posição de homens e mulheres ocupantes de funções (maio de 2010)

\begin{tabular}{|l|c|c|c|c|c|c|}
\hline \multirow{2}{*}{ Tipo de Função } & \multicolumn{2}{|c|}{ Mulheres } & \multicolumn{2}{c|}{ Homens } & $\begin{array}{c}\text { Total com } \\
\text { Função }\end{array}$ & $\begin{array}{c}\text { Percentual } \\
\text { do Efetivo }\end{array}$ \\
\hline $\begin{array}{l}\text { Apoio } \\
\text { Operacional/ } \\
\text { Técnico }\end{array}$ & 782 & $26,22 \%$ & 2.201 & $73,78 \%$ & 2.983 & $2,7 \%$ \\
\hline
\end{tabular}


continuação

\begin{tabular}{|l|c|c|c|c|c|c|}
\hline $\begin{array}{l}\text { Atividade } \\
\text { Especial }\end{array}$ & 6.216 & $22,19 \%$ & 21.797 & $77,81 \%$ & 28.013 & $25,8 \%$ \\
\hline Confiança & 4.618 & $32,28 \%$ & 9.689 & $67,72 \%$ & 14.307 & $13,18 \%$ \\
\hline Gerencial & 391 & $20,27 \%$ & 1.538 & $79,73 \%$ & 1.929 & $1,77 \%$ \\
\hline Gratificada & 702 & $45,85 \%$ & 829 & 54,15 & 1.531 & $1.41 \%$ \\
\hline Técnica & 872 & $47,26 \%$ & 973 & $52,74 \%$ & 1.845 & $1,7 \%$ \\
\hline Total & 13.581 & $26,83 \%$ & 37.027 & $73,17 \%$ & 50.608 & $46,6 \%$ \\
\hline
\end{tabular}

Fonte: Elaboração própria.

A tabela 2 mostra que cerca de $22 \%$ das mulheres foram contempladas com funções consideradas atividades especiais. Todavia, as atividades especiais não representam uma ascensão na carreira das trabalhadoras e trabalhadores. Contudo, apesar de não representar uma ascensão funcional, as atividades especiais implicam um acréscimo salarial importante para os ocupantes de cargos de nível médio. Além disso, atividades motorizadas estão associadas às características masculinas, o que tem pautado a luta das trabalhadoras para que tenham acesso às atividades especiais, como foi reiterado no acordo coletivo de 2009-2011, de maneira a garantir o "direito de igualdade na seleção para exercer a função motorizada".

As funções técnicas e gerenciais, por sua vez, representam um crescimento na carreira dos/as trabalhadores/as dentro da empresa.

Ao se analisar a distribuição de funções às trabalhadoras, verifica-se que as mulheres ocupavam quase $27 \%$ das funções, isto é, eram 13.581 trabalhadoras com função. Se considerarmos que eram 18.968 no total, há aí mais de $71 \%$ de mulheres contempladas com funções e atividades com gratificação, enquanto entre os homens o percentual era de 51\%. No entanto, é preciso eliminar o percentual considerado de apoio técnico e apoio operacional, bem como os dados sobre atividades especiais. Isso porque as primeiras abarcam um leque 
de atividades bastante variado na hierarquia da empresa, enquanto as atividades especiais não configuram ascensão.

Com esse recorte, são consideradas na análise $48,5 \%$ das mulheres com função na empresa que podem ter ascendido ou progredido na carreira. Averigua-se, pelos dados da tabela 2, que nas funções de confiança há a representatividade de 32,28\% de mulheres, enquanto na função gerencial o percentual é de $20,27 \%$. As funções técnicas, todavia, contam com o representativo percentual de $47,26 \%$ de mulheres, embora isso represente apenas 872 funcionárias em um universo de 108.516 (maio de 2010).

Por todos os ângulos, portanto, seja na estrutura hierárquica ou apenas em atividades operacionais, constata-se a ínfima participação das mulheres na força de trabalho dos Correios. De forma geral, portanto, as mulheres são contempladas com funções e atividades gratificadas na mesma proporção em que estão representadas na empresa.

Diante desse quadro, a ECT não ficou alheia ao Programa Pró-Equidade de Gênero da Secretaria de Políticas para Mulheres da Presidência da República. A estatal iniciou a adesão ao programa em novembro de 2011 com o intuito de melhorar as condições de inserção das mulheres. Como parte da adesão ao Programa, a empresa apresentou dados à Secretaria de Políticas para Mulheres que ajudam a detalhar o perfil da força de trabalho da empresa.

Nesse perfil da força de trabalho, a ECT informa que em 31 de dezembro de 2011 não havia nenhuma mulher ocupando cargos na alta direção da empresa. Em 2012, no entanto, houve pela primeira vez a nomeação de uma mulher para ocupar um cargo na cúpula da ECT. Além disso, entre os vinte e oito diretores regionais há duas mulheres - o que indica uma mudança. Segundo a estatal, durante o ano de 2011 houve a promoção de 118 mulheres e 310 homens a cargos de gerência e diretoria, isto é, a proporção de mulheres promovidas em 
relação aos homens foi de uma em cada três. Comparando com a baixa representatividade das mulheres na empresa, trata-se de um sinal de que as mulheres têm obtido vagarosamente a ascensão na estrutura da empresa.

Apesar da ascensão de poucas mulheres e da baixa presença feminina, a ECT não havia realizado nenhum estudo próprio para averiguar os possíveis fatores impeditivos à promoção das mulheres. Com isso, a empresa até o momento de adesão ao Programa também não havia implantado nenhuma política de incentivo à promoção das mulheres. A lógica da estatal se fundamenta em uma suposta objetividade e cientificidade dos critérios de ascensão e promoção instituídos no Plano de Cargos, Carreiras e Salários e pelas ferramentas de gestão de pessoas. Evidentemente, tais mecanismos impedem a percepção do problema ao apontarem critérios supostamente objetivos que dificultariam a ascensão das mulheres. A estatal, com isso, reitera a sua omissão em relação à baixa presença feminina entre seus funcionários: no início da década de 1990, a empresa não estimulou diretamente a presença de mulheres em sua força de trabalho operacional; até o momento, também tem deixado de promover a ascensão das trabalhadoras por se basear em ferramentas gerenciais supostamente neutras.

Todavia, criar e integrar aos instrumentos de gestão de pessoas mecanismos para aumentar a participação das trabalhadoras no corpo funcional da estatal é o objetivo do Programa Pró-Equidade de Gênero, do qual resultou o I Fórum dos Direitos Humanos e da Igualdade de Gênero e Raça nos Correios, no qual questões pertinentes aos temas foram apresentadas e oficinas para debate e formulação de propostas foram realizadas. Os resultados desses esforços iniciais, contudo, ainda não são visíveis para trabalhadores e trabalhadoras da estatal. 


\section{As “QUESTÕES DA MULHER" NAS REIVINDICAÇÕES SINDICAIS: REVENDO AS POLÍticas de GESTÃo do TRABALHO?}

Quais são as conquistas e reivindicação dos sindicatos ecetistas que perpassam as questões atinentes às relações sociais de sexo?

A Pauta de Reivindicações da Federação Nacional dos Trabalhadores em Correios e Telégrafos e Similares (FENTECT) para as negociações coletivas de 2009-2010 contemplou uma seção específica para as mulheres, denominada "Questão da Mulher", remetendo a uma representação masculina das reivindicações das trabalhadoras.

Baseada no histórico de negociações e nos acordos já estabelecidos com a empresa, a pauta propunha um avanço em algumas cláusulas. Assim, reivindicava a criação de uma comissão em cada diretoria regional com a participação sindical para apurar as denúncias de assédio moral e sexual e discriminação, bem como a demissão por justa causa do autor e posterior encaminhamento do caso à justiça. Todavia, o que a entidade sindical conquistou foi o compromisso da ECT em combater tais práticas, promover cursos e palestras e a necessidade de encaminhamento das denúncias para a diretoria regional para que fossem apuradas.

A FENTECT propôs ainda que a ECT disponibilizasse equipe multiprofissional para atendimento das trabalhadoras vítimas de violência doméstica, bem como a prestação de auxílios necessários à sua integridade física e psicológica, além da participação em campanhas públicas sobre o tema. Sobre isso, no entanto, não houve avanço e nada foi incluído no acordo. O quadro 1, apresentado a seguir, compara as reivindicações com viés de gênero e as conquistas no acordo coletivo: 
Quadro 1 - Reivindicações e conquistas das trabalhadoras

\begin{tabular}{|c|c|}
\hline Pauta de Reivindicação 2009 - 2010 & Acordo Coletivo 2009 - 2011 \\
\hline $\begin{array}{l}\text { Assédio Sexual, Moral e Psicológico } \\
\text { Criação de comissão paritária de } \\
\text { trabalhadores e sindicato em cada diretoria } \\
\text { regional para apurar os casos de assédio } \\
\text { moral e sexual, com demissão por justa } \\
\text { causa para o autor do assédio e estabilidade } \\
\text { para a/o assediada/o. }\end{array}$ & $\begin{array}{l}\text { Assédio Sexual e Assédio Moral } \\
\text { A ECT desenvolverá ações de sensibilização e } \\
\text { educação para combater o assédio sexual e } \\
\text { moral, prevenindo tais práticas e prestando apoio } \\
\text { psicológico aos envolvidos, caso solicitem. }\end{array}$ \\
\hline $\begin{array}{l}\text { Condições de trabalho da mulher } \\
\text { O peso máximo para as empregadas } \\
\text { movimentarem e transportarem não poderá } \\
\text { ser superior a } 5 \mathrm{~kg} \text {. } \\
\text { Banheiros femininos e fornecimento } \\
\text { de uniforme diferenciado e garantia à } \\
\text { empregada de exercer a função motorizada } \\
\text { [...] sem qualquer tipo de discriminação. }\end{array}$ & $\begin{array}{l}\text { Distribuição Domiciliária e Garantias às Empregadas } \\
\text { O limite de peso transportado pelo carteiro será de } \\
10 \text { kg para homem e } 8 \mathrm{~kg} \text { para a mulher. } \\
\text { As funcionárias que estiverem grávidas poderão } \\
\text { ter uma mudança provisória de suas atividades } \\
\text { de trabalho, desde que homologado pelo serviço } \\
\text { médico da empresa. } \\
\text { Banheiro feminino com ducha higiênica em todas as } \\
\text { edificações. } \\
\text { A ECT concederá às empregadas a prorrogação por } 60 \\
\text { dias da licença-maternidade, conforme estabelece a } \\
\text { Lei } 11.770 \\
\text { Igualdade na seleção para exercer a função } \\
\text { motorizada. } \\
\text { A ECT assegurará à empregada, durante a jornada } \\
\text { de trabalho de oito horas, um descanso especial } \\
\text { de duas horas ou dois descansos de uma hora para } \\
\text { amamentar o próprio filho, até que este complete } \\
\text { um ano de idade, podendo a jornada de trabalho ser } \\
\text { reduzida para seis horas. } \\
\text { As empregadas da ECT, mesmo quando se } \\
\text { encontrarem em licença médica, farão jus ao } \\
\text { pagamento de reembolso-creche até o final do ano } \\
\text { em que seu filho, tutelado ou menor sob guarda em } \\
\text { processo de adoção, atingir o sétimo aniversário. }\end{array}$ \\
\hline
\end{tabular}

Fonte: Pauta de Reivindicação e Acordo Coletivo 2009-2011. 
A maior parte das questões versa sobre as condições maternas das trabalhadoras, como se verifica no quadro. Sem deixar de reconhecer a importância de tais pleitos, sobretudo ao se relembrar que no acordo coletivo de 1995 as trabalhadoras conquistaram pela primeira vez uma cláusula garantindo o direito de amamentar o filho durante o expediente de trabalho, percebe-se que as reivindicações reiteram as imagens de gênero que associam o papel da mulher trabalhadora à figura abstrata de "mãe", reafirmada pela empresa e também pelos sindicatos.

O auxílio creche e babá que as trabalhadoras conquistaram ainda na década de 1990 representam, no entanto, uma ruptura com a ordem de gênero ao garantir às mulheres ecetistas condições de manterem seus filhos que tenham até sete anos de idade em creches durante o expediente de trabalho. Assim, há o reconhecimento de que as trabalhadoras exercem uma atividade profissional e, para o seu bom desempenho e livre exercício de sua cidadania, ter condições de pagar uma creche é fundamental. $\mathrm{O}$ valor do benefício, reajustado anualmente, representava quase a metade do salário básico dos trabalhadores operacionais, isto é, R\$ 360,20 em dezembro de 2010.

Todavia, deve-se registrar que há uma reivindicação - e mesmo uma polêmica - entre trabalhadores, que gostariam de receber o benefício. Homens só o recebem em casos especiais, ou seja, se for viúvo, pai solteiro ou separado com a guarda do filho. Em razão disso, são poucos os que têm acesso ao benefício. Em dezembro de 2010, por exemplo, eram 2.399 mulheres e 23 homens. Sendo assim, uma reivindicação dos trabalhadores é também receber o auxílio. A queixa mais ouvida entre os trabalhadores é que "as mulheres não têm filhos sozinhas", o que expressa como as representações de gênero na empresa ainda atribuem somente à mulher a responsabilidade pelo cuidado e manutenção dos filhos. 
Outra reivindicação presente na pauta de reivindicações das trabalhadoras versava sobre a "participação da mulher nas decisões da empresa". Para isso, pleiteava-se a inclusão de uma cláusula que obrigasse a "ECT a implementar, em parceria com a Secretaria da Mulher da FENTECT, ação afirmativa visando à valorização da mulher." No acordo 2009-2011, contudo, não houve a inclusão de tal compromisso no acordo coletivo. Na pauta 2011-2012, a FENTECT propôs também a adesão da ECT ao Programa Pró-Equidade de Gênero, decisão da empresa que já havia sido tomada antes da reivindicação. Neste item, portanto, a reivindicação foi extemporânea, com a empresa adiantando-se à demanda sindical. A decisão da empresa e a reivindicação sindical, no entanto, mostram, pelo menos, o reconhecimento da necessidade de medidas para melhor inclusão, permanência e ascensão das mulheres na estatal.

\section{Considerações Finais}

A despeito do incremento da participação feminina no mercado de trabalho, a dimensão estruturante inerente às relações sociais de sexo continua a influenciar o lugar das trabalhadoras nas organizações.

Nesse sentido, as relações sociais de sexo e as imagens de gênero presentes nos espaços organizacionais reproduzem a lógica social que impõe à força de trabalho feminina um papel secundário.

Ao analisar a divisão sexual do trabalho nos Correios, observa-se que a força de trabalho é majoritariamente masculina. Isso decorre da imagem de gênero que associa as atividades de trabalho na empresa a atributos supostamente masculinos como força física e condicionamento corporal para suportar o peso da carga transportada e intempéries durante a jornada de trabalho. 
Entre trabalhadores/as, a jocosidade dos homens acerca de supostas facilidades que as mulheres teriam por sua suposta fragilidade contrasta com os depoimentos das trabalhadoras, que afirmam realizar atividades iguais. Trata-se, assim, de compreender que as imagens de gênero que atribuem ao trabalho feminino um lugar inferiorizado continuam a operar entre os trabalhadores, reiterando a divisão sexual do trabalho no âmbito da estatal.

A imagem é reiterada não só entre trabalhadores/as. Sindicalistas, a despeito do discurso a favor da equidade entre os sexos, evidenciam suas percepções sobre as relações sociais de sexo quando denominam pontos da pauta de reivindicações de "questões da mulher", sendo a maior parte das reivindicações - elaboradas por homens - reiterações das imagens de gênero que associam as trabalhadoras à figura abstrata de "mãe", reforçando relações de sexo que atribuem à inserção profissional da mulher no mercado de trabalho um papel secundário. A qualificação do tema no âmbito sindical, portanto, é premente.

Isso se reflete na baixa presença de mulheres em posições de comando na estatal e também o pequeno percentual feminino na força de trabalho.

Ao aderir ao Programa Pró-Equidade de Gênero, os diretores dos Correios reconhecem a necessidade de implantar políticas de gestão que melhorem as condições de acesso, permanência e promoção das trabalhadoras na hierarquia profissional. Contudo, as ações iniciadas ainda são incipientes, não alterando o quadro apresentado.

\section{REFERÊNCIAS}

ABRAMO, Laís. Inserção das mulheres no mercado de trabalho na América Latina: uma força de trabalho secundária? In: HIRATA, Helena; SEGNINI, Liliana. (Org.). Organização, trabalho e gênero. São Paulo: Editora SENAC, 2007. p. 21-42. 
ARAÚJO, Angela Maria Carneiro. Os sentidos do trabalho da mulher em tempos de reestruturação produtiva. In: INTERNATIONAL CONGRESS ON WOMEN'S HEALTH ISSUES, 15., CONGRESSO ON OBSTETRIC AND NEONATAL NURSING, 4., 2004, Ribeirão Preto. Anais... Ribeirão Preto: USP, 2004. p.1-29.

BRUSCHINI, Cristina; LOMBARDI, Maria Rosa. Trabalho, educação e rendimentos das mulheres no Brasil em anos recentes. In: HIRATA, Helena; SEGNINI, Liliana (Org.). Organização, Trabalho e Gênero. São Paulo: SENAC, 2007, p. 42-88.

CARTEIRA é novidade no correio da região, Folha de São Paulo, São Paulo, 15 jul. 1992. Caderno Folha ABCD, Cidades, p. 6.

CORREIOS. Teste físico dos correios começam hoje. Blog dos Correios, 12 set. 2011. Disponível em: <http://blog.correios.com.br/correios/?p=705>. Acesso em: 9 ago. 2015.

DEVREUX, Anne-Marie. A teoria das relações sociais de sexo: um quadro de análise sobre a dominação masculina. Sociedade e Estado, Brasília, v. 20, n. 3, p. 561584, 2005.

HIRATA, Helena. Mundialização, divisão sexual do trabalho e movimentos feministas transnacionais. Cadernos de Crítica Feminista, Recife, ano III, n. 2, dez. 2009.

HIRATA, Helena; KERGOAT, Danièle. Novas configurações da divisão sexual do trabalho. Cadernos de Pesquisa, São Paulo, v. 37, n. 132, p. 595-609, 2007.

IMPORTÂNCIA mais do que reconhecida, CEP Brasil, nº. 43, 2004.

KERGOAT, Danièle. Dinâmica e consubstancialidade das relações sociais. Novos Estudos CEBRAP, São Paulo, n. 86, p. 93-103, mar. 2010.

KERGOAT, Danièle. Divisão sexual do trabalho e relações sociais de sexo. In: HIRATA, Helena et al. (Org.). Dicionário crítico do feminismo. São Paulo: Ed. UNESP, 2009. p. 67-75.

RIAL, Carmen; LAGO, Mara C. S.; GROSSI, Miriam Pillar. Relações sociais de sexo e relações de gênero: entrevista com Michèle Ferrand. Revista Estudos Feministas, Florianópolis, v. 13, n. 3, p. 677-690, 2005.

SALÁRIO atrai mulher a concurso de carteiros. Folha de São Paulo, São Paulo, 27 jan. 1992. Caderno Folha ABCD, Cidades, p. 8,

TEIXEIRA, Tadeu Gomes. O sistema postal brasileiro em transformação: regulação do mercado e reestruturação do modelo organizacional (1994-2011). Revista de Administração Pública, Rio de Janeiro, v. 48, n. 6, p. 1355-1380, 2014. 